\title{
SUPPLEMEN'TUM PRAEFATIONIS
}

\section{CONSPECTUS CODICLAI AD RECENSIONEM NON ADHIBITORUM}

Laurentranus 85,1 qui Oceanus appellatur [Bandini, catal. bibl. Laur. $\mathrm{H}$ III 236-247] bombyciuus forma maxima, saec. XIV ineuntis, foliorum 762 , Philoponi commentarium continet a fol. $510^{\mathrm{r}}-526^{\mathrm{r}}$. specimen dedit Guilelmus Stüve.

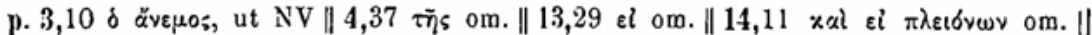

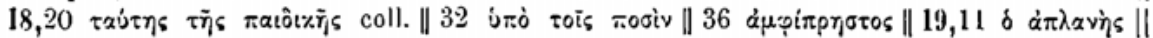

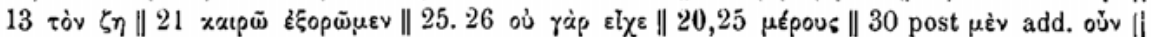

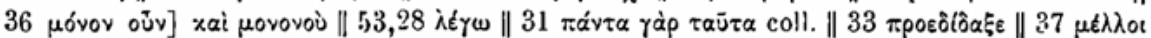

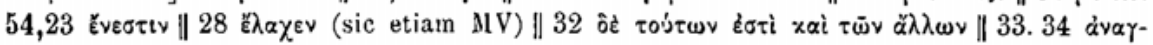

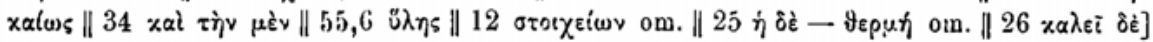

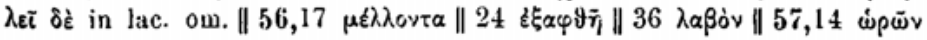

Parisinus Suppl. Gr. 556, ehartaceus forma maxima, saec. XVI, N f. $194^{r}$ sqq. Philoponum continet. specimina dedit Carolus Kalbfleisch.

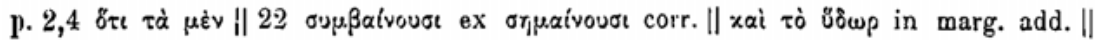

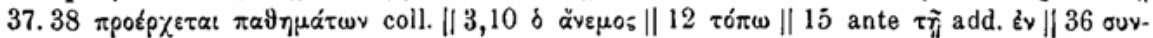

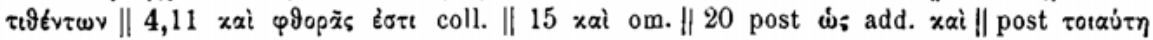

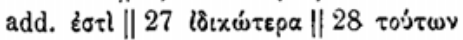

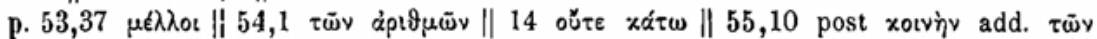

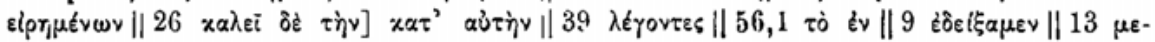

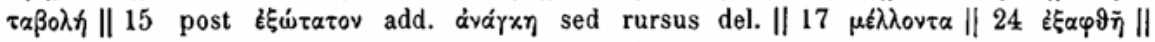

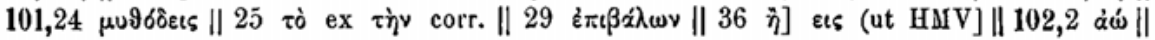

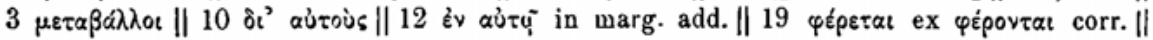

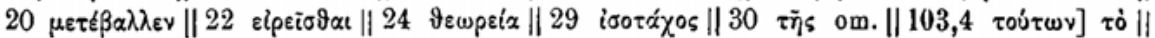

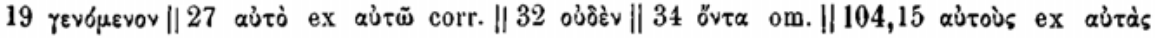

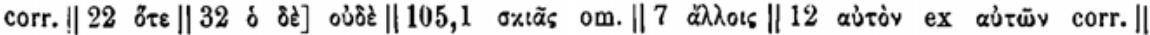
$13 \varepsilon \dot{u} \pi \varepsilon t \nabla \varepsilon \varepsilon i \varsigma$

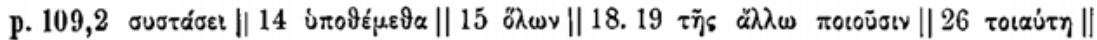

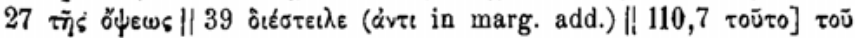

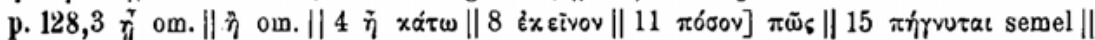

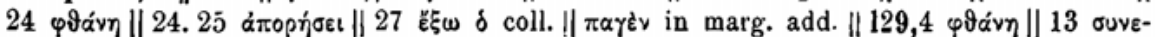

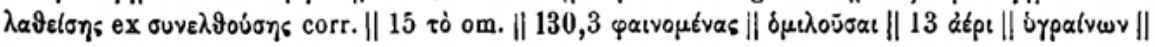




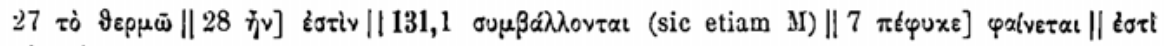

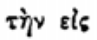

Marcianus 211, chartaceus, forma minore, saec. circiter XII [Zanetti, 0 Gr. S. Marci bibl. p. 114] continet Arist. de caelo, de generatione et corr., Meteorologica, Categorias cum Porphyrii Isagoge, de interpretatione, Metaphysica Aristotelis et Theophrasti, Themistii in Post. Anal. -

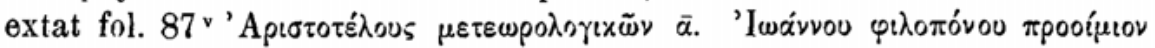

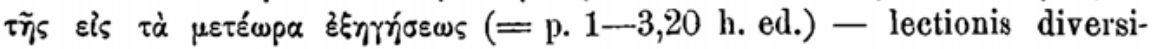
tatem notavit Guilelmus Stüve.

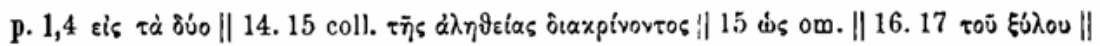

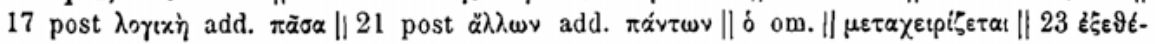

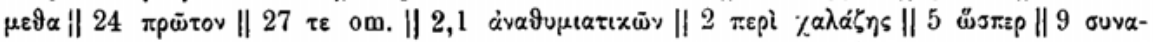

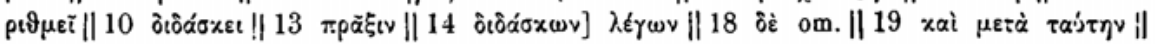

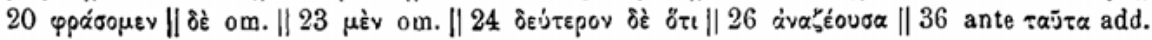

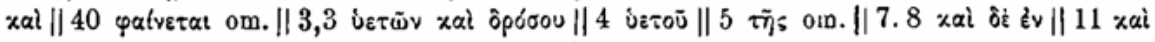

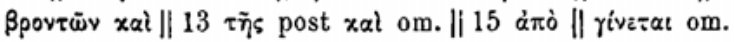

Escorialensis $\Phi-1-q$, chartaceus forma maxima, saec. XVI, ex Aldina, ut videtur, descriptus [ef. Stüve vol. XII,II p. xIv]; cuius libri mentionem fecisse satis habeo. 